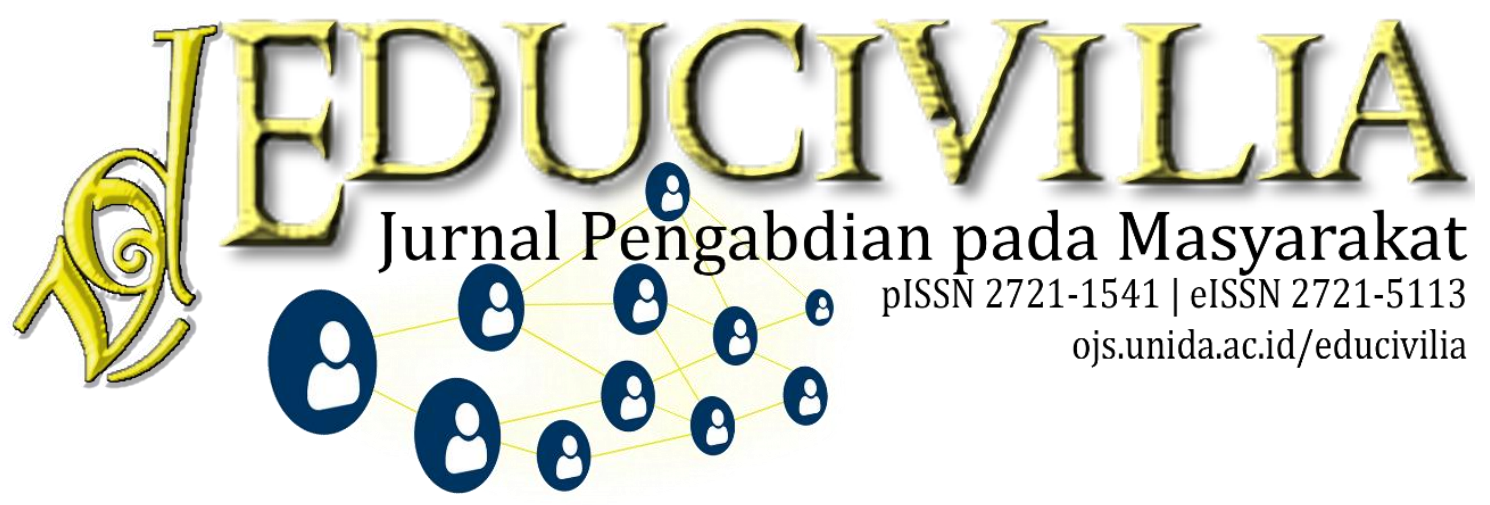

\title{
Upaya Pengembangan Stimulus Motorik Halus Pada Anak Retardasi Mental Kategori Sedang
}

Kilas Artikel

Volume 1 Nomor 2

Juli 2020: 87-95

DOI: $10.30997 /$ ejpm.v1i2.2836

Article History

Submission: 13-06-2020

Revised: 06-07-2020

Accepted: 11-07-2020

Published: 17-07-2020

Kata Kunci:

Cross Stitch

Motorik Halus

Retardasi Mental

Keywords:

Cross Stitch

Psychomotoric

Mental Retardation

Korespondensi:

Srinalesti Mahanani

nalesti.mahanani@gmail.com

\author{
Srinalesti Mahanani \\ STIKES RS Baptis Kediri
}

\begin{abstract}
Abstrak
Kemampuan anak retardasi mental perlu distimulasi terkait kemampuan motorik supaya dapat terampil menggunakan koordinasi tangan. Cross stitch adalah media yang saat ini dikembangkan tidak hanya sebagai seni namun sebagai stimulus motorik halus bagi anak. Kegiatan Pengabdian kepada Masyarakat ini dilaksanakan pada Siswa-siswi SLB Putera Asih Kota Kediri. Kegiatan diawali dengan pemberian pendidikan kesehatan pada guru kemudian tim pengabdi mengajarkan Cross Stitch Pada siswa. Dari 21 siswa terdapat 17 orang yang perlu mendapatkan bantuan penuh, dan 4 orang diantaranya dibantu sebagian. Beberapa siswa membawa alat ke rumah untuk berlatih bersama orang tua dan keluarganya. Pada kegiatan akhir pengabdian ini, persiapan alat dibantu oleh pengabdi dan guru. Pada tahap ini, siswa yang dibantu penuh adalah 15 orang dan 6 orang dibantu sebagian. Kegiatan cross stitch merupakan salah satu kegiatan yang dapat menstimulasi perkembangan motorik halus. Kegiatan tersebut akan dapat melenturkan jari, meningkatkan kemampuan koordinasi motorik halus dan meningkatkan stimulus otak bagi siswa berkebutuhan khusus.

\begin{tabular}{l} 
Efforts to Develop Fine Motor Stimulus in Children with \\
Medium Category Mental Retardation \\
Abstract \\
\hline Mental retardation children's abilities need to be stimulated related \\
to motor skills in order to be able to skillfully use hand coordination. \\
Cross stitch is a medium that is currently developed not only as an \\
art but as a fine motor stimulus for children. Community Service \\
Activities are carried out at Putera Asih SLB Students in Kediri \\
City. The activity begins with the provision of health education to \\
teachers then the service team teaches Cross Static students. From \\
21 students there were 17 people who needed full assistance, and 4 \\
of them were partially assisted. Some students bring tools home to \\
practice with their parents and family. In the final activity of this \\
service, the preparation of tools is assisted by devotees and teachers. \\
At this stage, students who are fully assisted are 15 people and 6 \\
people are partially assisted. Cross stitch activity is one of the \\
activities that can stimulate fine motor development. These activities
\end{tabular}
\end{abstract}

Educivilia: Jurnal Pengabdian pada Masyarakat is licensed under a Creative Commons Attribution-Share Alike 4.0 International License. Copyright @ 2020 Universitas Djuanda. All Rights Reserved p-ISSN 2721-1541 | e-ISSN 2721-5113 


\section{PENDAHULUAN}

Permainan edukatif adalah kegiatan yang meningkatkan suasana hati dan dapat berfungsi sebagai media pendidikan yang bersifat mendidik dan berguna untuk meningkatkan kemampuan berbahasa, berpikir serta bergaul dengan sosial masyarakat, meningkatkan kekuatan dan keterampilan anggota tubuh anak, membangun kepribadian, membangun ikatan (bonding) antara guru dengan siswa, yang selanjutnya menyalurkan bakat dan minat anak didik. Permainan edukatif dapat dimaknai sebagai suatu kegiatan yang dilakukan untuk memperoleh kesegaran pikiran dari cara atau media pendidikan yang dikemas dalam kegiatan bermain, kegiatan ini memiliki muatan pendidikan yang dapat bermanfaat dalam mengembangkan bakat siswa. Dapat dimaknai bahwa permainan edukatif merupakan sebuah bentuk kegiatan membangun kognitif yang dilakukan dengan menggunakan media permainan.

Anak-anak usia 2-8 tahun merupakan anak pada tahap praoperasional. Menurut Piaget ciri pokok perkembang- an pada tahap ini adalah pada penggunaan simbol atau bahasa tanda, dan mulai berkembangnya konsep-konsep intuitif. Usia 2-4 tahun (Tahap Praoperasional) pada usia ini anak mampu mengolah kata untuk mengembangkan konsep berpikir yang sederhana. Karakteristik anak diantaranya adalah (1) Self Counter yang sangat dominan (2) Mampu mengelompokkan objek pada tingkat dasar berdasarkan ciri benda yang mencolok (3) Belum mampu memusatkan perhatian pada beberapa objek bersamaan. (4) Mampu mengelompokkan benda sesuai kriteria. (5) Mampu menata benda secara berderet, namun belum dapat menjelaskan perbedaan antara deretan.

Usia 4-8 tahun (Tahap Intuitif) anak akan berkarakteristik: (1) mampu membentuk kelompok benda-benda, namun kurang memahami secara sadar tujuan penyusunan tersebut. (2) anak mulai memahami kaitan yang logis pada halhal kompleks, (3) anak mampu menginisiasi melakukan sesuatu dalam beberapa ide, (4) anak mampu menerima penjelasan prinsip dengan benar. 
Bentuk pendidikan pada anak usia dini yaitu 0-8 tahun adalah memodifikasi tempat belajar untuk dapat sekaligus menjadi bermain bagi anak. Siswa akan diajarkan mengenal disiplin, aturan, tanggung jawab serta kemandirian melalui berbagai permainan. Anak akan belajar bahwa mereka harus beradaptasi dengan lingkungannya, membangun empati dengan teman serta belajar bekerja sama dengan anak lain yang seusia.

Kegiatan bermain yang mengandung edukasi akan mengasah daya pikir anak untuk menstimulasi perkembangan emosi, sosial dan fisik secara simultan. Setiap anak memiliki minat dan kemampuan bermain yang berbeda sesuai perkembangan usia anak. Metode bermain juga dapat akan menimbulkan fantasi besar oleh dan menumbuhkan rasa ketertarikan anak pada pelajaran dan permainan tersebut.

Saat usia masih anak, itu merupakan masa emas (the golden age). Bahkan sekitar 50\% kecerdasan orang dewasa sudah terjadi ketika mereka berusia empat tahun. Peningkatan berikutnya 30\% pada usia 8 tahun, dan $20 \%$ sisanya pada pertengahan. (Loeziana Uce, 2017). Terdapat perbedaan prinsip pertumbuhan dan perkembang anak dari UNESCO dan Undang-Undang di Indonesia, dimana usia 6 sampai 8 tahun merupakan usia transisi dari masa anak-anak yang masih memerlukan bantuan (dependen) ke masa anak-anak yang mulai mampu mandiri (independen), baik dari segi fisik maupun psikis. Dalam sistem pembelajaran anak harus terkandung perkembangan psikomotorik. Dalam perkembangan motorik terdapat dua jenis, yaitu motorik kasar dan motorik halus. Dalam kurikulum belajar anak terdapat pelajaran keterampilan. Namun pelajaran keterampilan yang diberikan secara umum yaitu mewarnai, menggunting dan menempel.

Retardasi mental adalah suatu kondisi ketidakcukupan mental yang ditandai oleh intelegensi yang rendah yang mengakibatkan keterbatasan individu untuk belajar dan beradaptasi terhadap standar masyarakat atas kemampuan yang dianggap normal. (Imas Cahyaning Pratiwi, Oktia Woro Kasmini Handayani, 2017). Retardasi mental adalah fungsi intelektual umum dibawah normal yaitu 70 dan memiliki kendala dalam perilaku adaptif sosial serta gejala yang timbul dalam masa perkembangan, yaitu di bawah usia 18 tahun. (Mut- 
Upaya Pengembangan Stimulus Motorik Halus Pada Anak Retardasi ...

taqin, 2012). Retardasi mental didefinisikan dalam hal kognitif (IQ di bawah 70) dan fungsi adaptif, dan merupakan kondisi yang terjadi sebelum usia 18 tahun. Tunagrahita adalah seseorang dikategorikan berkelainan mental subnormal atau tunagrahita," jika ia memiliki tingkat kecerdasan yang sedemikian rendahnya (di bawah normal), sehingga untuk meneliti tugas perkembangannya memerlukan bantuan atau layanan secara spesifik, termasuk dalam program pendidikannya. (Afnita Usti, 2013).

Pengelompokkan anak tunagrahita terdiri dari beberapa grade diantaranya adalah (1) Debil (anak tunagrahita mampu didik) yaitu anak tunagrahita yang tidak mampu mengikuti pada program sekolah biasa, namun ia masih terdapat kemampuan yang bisa dikembangkan melalui pendidikan, sekalipun hasilnya tidak maksimal. (2) Imbecil (Anak tunagrahita mampu latih) yaitu anak tunagrahita dengan kecerdasan sedemikian rendahnya sehingga tidak dapat mengikuti program pendidikan yang diperuntukkan bagi anak tunagrahita mampu didik. (3) Idiot (Anak tunagrahita mampu rawat) yaitu anak tunagrahita dengan kecerdasan sangat rendah yang mengakibatkan ia tidak mampu sosialisasi bahkan mengurus diri sendiri (Desni Humaira, 2012).

Angka kejadian pada retardasi mental di negara maju sekitar 1-3\%. (Sebastian dalam Soetjiningsih dan Ranuh, 2013). Data survei menyebutkan jumlah anak retardasi mental adalah 3\% dari jumlah penduduk Indonesia. Retardasi mental mengenai 1,5 kali lebih banyak pada laki-laki dibandingkan dengan perempuan (Sularyo, 2016). Data pada tanggal 26 April 2016 diperoleh jumlah data anak dengan retardasi mental sedang di Sekolah Luar Biasa Tunagrahita (C1) Putera Asih Kota Kediri sebanyak 48 anak, yang terdiri dari 34 anak untuk tingkat SD, 8 anak untuk tingkat SMP, dan 5 anak untuk tingkat SMA. Berdasarkan jenis kelamin didapatkan anak laki-laki berjumlah 22 anak dan 26 untuk anak perempuan

Cross stitch merupakan salah satu keterampilan yang berasal dari Mesir abad ke 200-500 Masehi yang kemudian meluas ke dinasti Tang China hingga ke Eropa. Cross stitch juga telah ada di Indonesia pada saat jaman penjajahan Belanda. Cross stitch adalah media yang saat ini dikembangkan tidak hanya 
Educivilia: Jurnal Pengabdian pada Masyarakat Volume 1 Nomor 2, Juli 2020

sebagai seni namun sebagai stimulus motorik halus bagi anak. Kemampuan anak retardasi mental perlu distimulasi terkait kemampuan motorik supaya dapat terampil menggunakan koordinasi tangan.

\section{METODE}

Metode pendekatan yang ditawarkan untuk Aplikasi Edukasi Cross Stitch Pada Anak Dengan Retardasi Mental di Kelas C-1 dan C SLB Putera Asih Sebagai Stimulus Motorik Halus dengan metode ceramah dan pelatihan serta dilakukan monitoring setiap bulannya.

Prosedur kerja yang direncanakan untuk mendukung metode kerja yang ditawarkan yaitu Pelaksanaan Pendidikan Kesehatan Orang Tua dan Anak dengan Retardasi Mental Upaya Mengoptimalkan Tugas Keluarga dalam Merawat Anak dengan Kebutuhan Khusus di SLB Putra Asih Kediri tujuan yang diharapkan yaitu Meningkatkan pengetahuan serta perilaku orang tua dan guru dalam merawat anak dengan kebutuhan khusus. Pertama Tim pengabdi kegiatan akan membuat surat permohonan surat tugas dari Institusi untuk melaksanakan kegiatan pengabdian kepada masyarakat yang akan dilaksanakan di SLB Putra Asih Kediri.
p-ISSN 2721-1541 | e-ISSN 2721-5113 || 91

DOI: $10.30997 /$ ejpm.v1i2.2836

Berdiskusi dengan Kepala Sekolah SLB Putra Asih Kediri dalam Pelaksanaan Pendidikan Kesehatan Orang Tua dan Anak dengan Retardasi Mental Upaya Mengoptimalkan Tugas Keluarga dalam Merawat Anak dengan Kebutuhan Khusus di SLB Putra Asih Kediri.

Menetapkan waktu dan tempat yang disepakati oleh tim pengabdi dan mitra (SLB Putra Asih Kediri). Membuat undangan kepada guru dan orang tua untuk Pelaksanaan Pendidikan Kesehatan Orang Tua dan Anak dengan Retardasi Mental Upaya Mengoptimalkan Tugas Keluarga dalam Merawat Anak dengan Kebutuhan Khusus di SLB Putra Asih Kediri selama 1 hari dan dilakukan monitoring setiap bulannya.

\section{HASIL \& PEMBAHASAN}

Kegiatan pengabdian kepada masyarakat di SLB "Putera Asih" Kota Kediri dengan tema Aplikasi Edukasi Cross Stitch Pada Anak Dengan Retardasi Mental dilaksanakan selama 2 bulan yaitu pada tanggal 10 November 2017 untuk pengambilan data awal dan mengajarkan memegang kain, benang dan jarum untuk pembuatan cross stitch dan 8 Desember 2017 mengajarkan melanjutkan kegiatan cross stitch. 
Tabel 1 Distribusi Frekuensi Jenjang Kelas Siswa SLB Putera Asih Kota Kediri NovemberDesember 2017

\begin{tabular}{cccc}
\hline \multirow{2}{*}{ No } & \multirow{2}{*}{ Jenjang Kelas } & \multicolumn{2}{c}{ Jumlah } \\
\cline { 3 - 4 } & & $\mathrm{f}$ & $\%$ \\
\hline 1 & Kelas 7 & 8 & 38,09 \\
\hline 2 & Kelas 8 & 5 & 23,81 \\
\hline 3 & Kelas 9 & 3 & 14,29 \\
\hline 4 & Kelas 10 & 5 & 23,81 \\
\hline & Total & 21 & 100 \\
\hline
\end{tabular}

Tabel 2 Distribusi Frekuensi Jenis Kelamin Siswa SLB Putera Asih Kota Kediri November-Desember 2017

\begin{tabular}{cccc}
\hline \multirow{2}{*}{ No } & \multirow{2}{*}{ Jenis Kelamin } & \multicolumn{2}{c}{ Jumlah } \\
\cline { 3 - 4 } & & $\mathbf{f}$ & $\mathbf{0}$ \\
\hline 1 & Laki-laki & 11 & 52,38 \\
\hline 2 & Perempuan & 10 & 47,62 \\
\hline & Total & 21 & 100 \\
\hline
\end{tabular}

Tabel 3 Distribusi Frekuensi Kemampuan Motorik Siswa SLB Putera Asih Kota Kediri NovemberDesember 2017

\begin{tabular}{clcccc}
\hline \multirow{2}{*}{ No } & Kemampuan & \multicolumn{2}{c}{ Sebelum } & \multicolumn{2}{c}{ Sesudah } \\
\cline { 3 - 6 } & Motorik Halus & $\mathrm{f}$ & $\%$ & $\mathrm{f}$ & $\%$ \\
\hline 1 & Dibantu Penuh & 17 & 80,95 & 15 & 71,43 \\
\hline 2 & $\begin{array}{l}\text { Dengan } \\
\text { Bantuan }\end{array}$ & 4 & 19,05 & 6 & 28,57 \\
\hline 3 & Mandiri & 0 & 0 & 0 & 0 \\
\hline & Total & 21 & 100 & 21 & 100 \\
\hline
\end{tabular}

Strategi pembelajaran anak tunagrahita ringan atau disebut juga strategi instruksional adalah susunan rencana kegiatan belajar yang paling efektif dan efisien untuk mendapatkan pengalaman belajar anak tunagrahita ringan agar tercapai tujuan instruksional yang ditetapkan. Kegiatan cross stitch (menyulam) untuk siswa normal pada umumnya. Video untuk siswa tunagrahita ringan disajikan dengan keterangan gam- bar detail dengan adanya penomoran angka pada tiap titik motif untuk memudahkan siswa memahami arah keluar masuknya jarum pada motif. Motif yang diajarkan adalah motif sesederhana mungkin agar mudah diikuti.

Siswa tunagrahita ringan adalah anak yang memiliki keterbatasan dalam hal kecerdasan dan adaptasi sosial. Anak tunagrahita ringan sangat kesulitan dalam kemampuan berpikir dalam bidang akademik terutama untuk halhal yang bersifat abstrak, maka untuk mengembangkan anak tunagrahita ringan adalah melalui bidang sosial dan keterampilan. Keterampilan diberikan kepada anak tunagrahita ringan agar dapat mengembangkan potensi dirinya dan hidup mandiri. Salah satu bentuk mata pelajaran keterampilan yang diajarkan pada siswa tunagrahita ringan adalah keterampilan menyulam. Pada kegiatan pengabdian dengan tema keterampilan menyulam ini siswa tunagrahita ringan diajarkan mengenal macam-macam tusuk hias. Dalam menyulam, ketelatenan, ketelitian, dan kemampuan dalam mengingat memiliki tantangan tersendiri untuk siswa tunagrahita ringan mengingat bahwa siswa tunagrahita ringan memiliki keterbatas- 
Educivilia: Jurnal Pengabdian pada Masyarakat Volume 1 Nomor 2, Juli 2020

an dalam hal daya ingat. Oleh karena itu, peran guru pada saat proses pembelajaran menjadi sangat penting untuk dapat mendampingi siswa yang memiliki keterbatasan tersebut. Kenyataannya pada saat proses pembelajaran pengabdi dan guru perlu mendampingi penuh pada beberapa siswa.

Menurut Christiana (2016), untuk meningkatkan motorik halus pada anak maka dibutuhkan beberapa kegiatan keterampilan. Berikut ini adalah kegiatan yang dapat dilakukan oleh anak anak, yaitu: membatik, meronce, menggambar dan menyulam. Ada 3 jenis membatik, antara lain: Membatik dengan pastel, membatik sederhana, dan membatik dengan teknik tutup celup. Meronce merupakan salah satu bentuk keterampilan anak atau salah satu stimulus untuk mengasah kemampuan motorik anak yang dapat melatih otot-otot tangan termasuk koordinasi mata, tangan, dan pikiran. Sedangkan manfaat meronce adalah melatih kemampuan jari dan bermanfaat sebagai dasar kemampuan memegang pensil. Cross stitch adalah salah satu yang termasuk ke dalam pelajaran keterampilan, maka untuk konsep pembelajaran yang diterapkan adalah belajar sam-
p-ISSN 2721-1541 | e-ISSN 2721-5113

DOI: 10.30997/ejpm.v1i2.2836

bil bermain. Sebagaimana Plato, Aristoteles, dan Frobel menganggap bermain sebagai kegiatan yang mempunyai nilai praktis. Artinya bermain digunakan sebagai media untuk meningkatkan keterampilan dan kemampuan tertentu pada anak. Bagi anak bermain adalah kegiatan yang serius namun mengasyikkan. Berbeda dari pelajaran sekolah, edukasi cross stitch adalah keterampilan tangan yang memberikan hiburan pada anak. Hiburan yang dimaksud adalah anak mempelajari keterampilan dengan cara yang berbeda, tidak seperti menggambar yang dengan memberikan warna di kertas, cross stitch memiliki cara yang berbeda.

Beberapa penelitian yang telah dilakukan oleh berbagai bidang ilmu untuk mengembangkan cross sticth untuk anak, khususnya bagi anak dengan kebutuhan khusus. Penelitian Putri (2014) tentang pengembangan media video mata pelajaran keterampilan menyulam untuk siswa tunagrahita ringan mendapatkan hasil pengembangan berupa (1) media video mata pelajaran keterampilan menyulam untuk siswa tunagrahita ringan kelas XII yang sesuai dengan materi dalam silabus dan RPP yang diterapkan di sekolah (2) 
Upaya Pengembangan Stimulus Motorik Halus Pada Anak Retardasi ...

Media video pembelajaran layak digunakan untuk siswa tunagrahita ringan kelas XII di SMA Luar Biasa Negeri 1 Yogyakarta dari aspek media dan aspek materi. Kelayakan media video pembelajaran berdasarkan penilaian validator mencapai persentase sebesar $100 \%$, maka media video ini dinyatakan layak untuk diujikan ke lapangan. Dari uji coba skala kecil hasilnya adalah $72,50 \%$ tergolong dalam kategori layak. Selanjutnya pada uji coba luas pada 4 siswa tunagrahita ringan hasilnya adalah 74,37\%, sehingga menyatakan media video mata pelajaran keterampilan menyulam layak digunakan sebagai media pembelajaran bagi siswa tunagrahita kelas XII di SMA Luar Biasa Negeri 1 Yogyakarta.

Pengembangan yang lain dilakukan oleh Christiana (2016) yaitu perancangan buku edukasi cross stitch melalui cerita bergambar bertujuan untuk mengajak dan memperkenalkannya kepada anak-anak. Harapan saat bermain cross stitch anak dapat mengasah perkembangan motorik halus mereka. Pendekatan ilustrasi yang digunakan adalah gaya kartun dan warna - warna cerah untuk meningkatkan minat baca anak. Dengan pendekatan komunikasi visual yang dituangkan dalam buku cerita bergambar ini diharapkan pembaca dapat mengenal lebih baik tentang cross stitch.

Pada kegiatan awal pengabdian ini, kegiatan menyulam yang diawali dengan persiapan alat diantaranya memasukkan jarum yang dilakukan oleh pengabdi dan guru. Selanjutnya siswa berusaha memasukkan jarum kedalam kain strimin. Dari 21 siswa terdapat 17 orang yang perlu mendapatkan bantuan penuh, dan 4 orang diantaranya dibantu sebagian. Beberapa siswa membawa alat ke rumah untuk berlatih bersama orang tua dan keluarganya. Pada kegiatan akhir pengabdian ini, persiapan alat dibantu oleh pengabdi dan guru. Pada tahap ini, siswa yang dibantu penuh adalah 15 orang dan 6 orang dibantu sebagian.

Kegiatan melatih motorik halus ini perlu terus dikembangkan. Keterampilan dapat dilakukan dengan beberapa metode selain menyulam yaitu menggambar, menempel, membuat mozaik dan meronce. Kegiatan tersebut akan dapat melenturkan jari, meningkatkan kemampuan koordinasi motorik halus 
Educivilia: Jurnal Pengabdian pada Masyarakat

Volume 1 Nomor 2, Juli 2020

dan meningkatkan stimulus otak bagi siswa berkebutuhan khusus.

\section{SIMPULAN}

Kegiatan cross stitch merupakan salah satu kegiatan yang dapat menstimulasi perkembangan motorik halus. Kegiatan tersebut akan dapat melenturkan jari, meningkatkan kemampuan koordinasi motorik halus dan meningkatkan stimulus otak bagi siswa berkebutuhan khusus.

\section{UCAPAN TERIMA KASIH}

Terimakasih kepada Kepala Sekolah dan seluruh Guru SLB Putera Asih Kota Kediri yang senantiasa mendukung pelaksanaan kegiatan pengabdian kepada masyarakat ini sehingga dapat terlaksana dengan lancar.

\section{DAFTAR PUSTAKA}

Afnita Usti. (2013). Meningkatkan Kemampuan Mengenal Angka Melalui Bermain Pancing Angka Bagi Anak Tunagrahita RIngan. EJUPEKhu (JURNAL ILMIAH PENDIDIKAN KHUSUS), 2(1). Retrieved from http://ejournal.unp.ac.id/index.p hp/jupekhu

Desni Humaira. (2012). Pelaksanaan Pembelajaran Bahasa Indonesia Bagi Anak Tunagrahita Ringan Kelas III Di SLB Sabiluna Pariaman. E-JUPEKhu (JURNAL ILMIAH PENDIDIKAN KHUSUS), 1(3). Retrieved from http:/ / ejournal.unp.ac.id/index.p $\underline{\mathrm{hp} / \text { jupekhu }}$
p-ISSN 2721-1541 | e-ISSN 2721-5113 DOI: $10.30997 /$ ejpm.v1i2.2836

Imas Cahyaning Pratiwi, Oktia Woro Kasmini Handayani, B. B. R. (2017). Kemampuan Kognitif Anak Retardasi Mental Berdasarkan Status Gizi. Public Health Perspective Journal, 2(1). Retrieved from https://journal.unnes.ac.id/sju/in dex.php/phpj

Loeziana Uce. (2017). THE GOLDEN AGE : MASA EFEKTIF MERANCANG KUALITAS ANAK. Bunayya: Jurnal Pendidikan Anak.

Muttaqin, A. (2012). Pengantar Asuhan Keperawatan Dgn Gangguan Sistem Persarafan. Kediri: Salemba Medika. Sularyo, T. S. (2016). Retardasi Mental. Sari Pediatri, 2(3). Retrieved from https://webcache.googleuserconte nt.com/search?q=cache:_0CEPxN7 xAIJ:https://saripediatri.org/inde x.php/saripediatri/article/download/1036/9 $\underline{66+\& c d=1 \& h l=i d \& c t=c \operatorname{lnk} \& g l=i d}$ 